\title{
RELIABLE SIMULATION OF METAL SURFACE PENETRATION BY LIGHTNING CONTINUING CURRENTS*
}

\author{
W. Zischank and F. Drumm \\ Universität der Bundeswehr München \\ Fakutät für Elektrotechnik, ET/7 \\ D-85577 Neubiberg \\ Germany \\ Telephone: ++498960063721 FAX: ++49896004 3723 \\ R. J. Fisher, G.H. Schnetzer, and M.E. Morris \\ Sandia National Laboratories \\ Electromagnetic Analysis and Test Department \\ P.O. Box 5800-0865 \\ Albuquerque, NM 87185, USA \\ Telephone: 505-845-8647 FAX: 505-844-7857
}

\begin{abstract}
A program with the ultimate aim of quantifying the fidelity of laboratory test techniques used to simulate the penetration of metallic surfaces by lightning continuing currents has been undertaken. Descriptions of the program methodology, dominant factors found to influence test results, and data obtained so far are given. Based on considerations of fundamental arc phenomenology and on the acquired experimental data, a standard test configuratiơn has been established, which has been demonstrated at two independent laboratories to produce consistent results that are generally corroborative of techniques suggested elsewhere in the lightning literature.
\end{abstract}

\section{INTRODUCTION}

Of specific interest to Sandia National Laboratories is the assessment and reduction of the potential safety threat posed by the penetration of metallic casings of munitions due to the direct attachment of lightning strikes. Laboratory tests using the Sandia Lightning Simulator (SLS) (1) have resulted in the complete penetration of even relatively thick materials, such as $3.8-\mathrm{mm}$ stainless steel, using severe but credible lightning continuing currents. Of fundamental importance in the interpretation of such test results is the degree of simulation fidelity inherent in the test technique vis-à-vis corresponding natural lightning currents of the same magnitude and waveshape. The degree of damage produced at the interface of an electrical arc and a metallic surface is a complicated function of many physical factors. At the first order level, these include electrode and test surface materials, condition, and geometry; arc length and polarity; ambient pressure; and arc current parameters. Since the SLS replicates both typical stroke and continuing current components of natural lightning exceptionally well, it was felt that the uncertainties regarding test fidelity were dominated by the other listed factors.

To asses the validity of the Sandia test results, an attempt was made to quantify the correspondence of the laboratory test technique to the process of the attachment of natural lightning to metallic surfaces. To this end, during 1989 an extensive literature review was conducted (2). While this effort provided considerable insight into the major factors that are involved and revealed several aspects of Sandia's then currently employed test technique that deviated from those being used at other test facilities, no adequate audit trail quantitatively linking accepted test practices to real lightning arcs

This work was partially supported by the U.S. Department of Energy under Contract DE-AC04-94AL85000. 
was discovered. As a result, experiments were then designed and fielded during 1990 (3) and 1991 (4) in which aluminum, ferrous and stainless steel, copper and titanium samples were exposed to triggered lightning strikes. The acquired damage spots, correlated with the measured stroke and continuing currents that produced them, established a set of benchmark data points produced by real lightning arcs. The next step was an attempt to reproduce the same current waveforms in the SLS and compare results obtained in the laboratory using various combinations of test electrode geometries and spacings with those of the benchmark lightning damage samples. Several important results reported earlier (eg., 5, 6) were confirmed, and additional quantitative data were obtained. The main conclusions at the time were as follows: damage is a very strong function of the waveform of the applied current, and total charge transfer is a completely inadequate test specification for lightning assessments; at least over the range of continuing currents of peak amplitudes of 200 to $700 \mathrm{~A}$, results are qualitatively independent of the electrode geometry (pointed tungsten or tungsten with an electrode jet diversion feature, hereafter referred to as an indirect electrode) but are more consistent on a shot-to-shot basis using the indirect electrode; over the same current range, which represents the limits of the Sandia continuing current generator, the results are qualitatively independent of interelectrode spacings from 1.3 to $2.5 \mathrm{~cm}$; and, finally, qualitatively good to excellent replication of the triggered lightning damage spots were obtained for $\mathrm{Al}, \mathrm{Cu}$, ferrous and stainless steel in terms of radius and appearance of the corresponding damage spots. A tentative "standard" test configuration using the jet diversion electrode, a dielectric arc spot restricting aperture over the test surface, and an interelectrode gap of $2.5 \mathrm{~cm}$ was established on the basis of the preliminary results.

Unfortunately, during these experiments it became immediately evident that, for any given test electrode configuration and spacing, the waveshape of the applied current was the dominant factor controlling damage. Limitations of the Sandia continuing current generator, which produces an exponentially decaying current with an approximately 0.5 -s decay constant, would not allow a close enough reproduction of the recorded triggered lightning currents to permit the desired direct calibration of laboratory results vs. real lightning damage spots.

A collaborative effort was then initiated with the University of the Armed Forces in Munich (UAFM) in which a systematic series of tests was performed by them using their laboratory capability for producing constant current waveforms of up to 1-s duration over a range of 50 to $1000 \mathrm{~A}$. The specific objectives of these tests included the independent confirmation of the earlier results related to electrode geometry and spacing, and the development of a detailed data set against which an advanced twodimensional thermal transport model of lightning spot damage could be subsequently validated. If this validation is achieved for the constant current data spots, the model will then be driven by the measured triggered lightning current, thereby being further validated against the benchmark spots produced by real lightning. The final step will be to compare results from the (presumably) validated model driven by time varying current waveforms realizable in the laboratory against test results acquired with those same currents. In this way, an indirect quantification of the uncertainty bounds on the fidelity of laboratory test results obtained with any arbitrary specified current waveform will be achievable.

The remainder of this paper represents the first report of the data and overall conclusions obtained so far from the constant current experiments carried out by the UAFM. In effect, we present here a snap-shot report of an on-going effort.

\section{ELECTRODE JET PHENOMENON}

Due to the limited source voltage available in laboratory simulations of continuing currents, in order to sustain an arc it is necessary to position a test electrode, referred 


\section{DISCLAIMER}

This report was prepared as an account of work sponsored by an agency of the United States Goverament. Neither the United States Government nor any agency thereof, nor any of their employees, makes any warranty, express or implied, or assumes any legal liability or responsibility for the accuracy, completeness, or usefulness of any information, apparatus, product, or process disclosed, or represents that its use would not infringe privately owned rights. Reference herein to any specific commercial product, process, or service by trade name, trademark, imanufacturer, or otherwise does not necessarily constitute or imply its endorsement, recommendation, or favoring by the United States Goverameat or any agency thereof. The views and opinions of authors expressed herein do not necessarily state or refiect those of the United States Government or any agency thereof. 


\section{DISCLAIMER}

Portions of this document may be illegible in electronic image products. Images are produced from the best available original document. 
to hereafter as a counter electrode, close to the specimen under test. This represents a major departure from a natural lightning attachment to such a surface. As has been documented earlier (e.g., 5, 7), the interaction of jets of ions and vaporized material originating from the surfaces of the counter electrode and specimen surface can cause shot-to-shot inconsistencies and either over- or undertesting with respect to effects produced by natural lightning of the same current parameters.

An explanation of the electrode jet was first given by Maecker (8) based on magnetic self compression in an arc and the development of a strong net longitudinal pressure gradient in the vicinity of the arc root on an electrode surface. Since this explanation has not been found elsewhere in the lightning technical literature, it is summarized here.

Current flowing in a straight conductor is surrounded by an azimuthal magnetic field $H$. A volume element of this conductor carrying a current density $j$ undergoes a perpendicular force $F\left(N / \mathrm{m}^{3}\right)$ given by the Lorentz relationship

$$
F=\mathbf{j} \times B
$$

where $B$ is the magnetic flux density given by $B=\mu H$. The force $F$ and the resultant magnetic pressure on the conductor is everywhere radially inward. For a solid conductor, it is of negligible significance. In the case of an arc burning in a compressible gas, however, this force works in a direction to constrict the arc channel until an equilibrium point is reached between the inward magnetic force and the internal kinetic pressure $p$ of the heated gases within the column; that is:

$$
\operatorname{grad} p=\mathbf{j} \times \mathbf{B} \text {. }
$$

For a symmetric arc (Figure 1 ) carrying a constant current density $j=i /\left(\pi R^{2}\right)$, the inward pressure as a function of the radius $r$ from the center of the arc can be calculated (8) as

$$
p(r)=p_{0} \cdot\left(1-\frac{r^{2}}{R^{2}}\right), \quad p_{o}=\frac{\mu_{0} \cdot i^{2}}{4 \pi^{2} R^{2}}
$$

with $p_{o}$ being the pressure in the arc center, where $r=0$. From Eqn. 3 it is seen that the magnetic pressure is inversely proportional to the cross sectional area $\left(\pi R^{2}\right)$ of the arc.

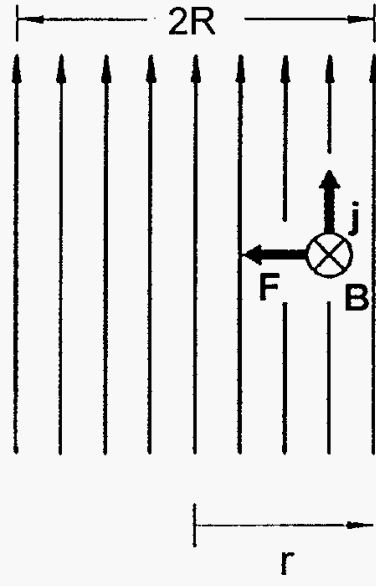

(a)

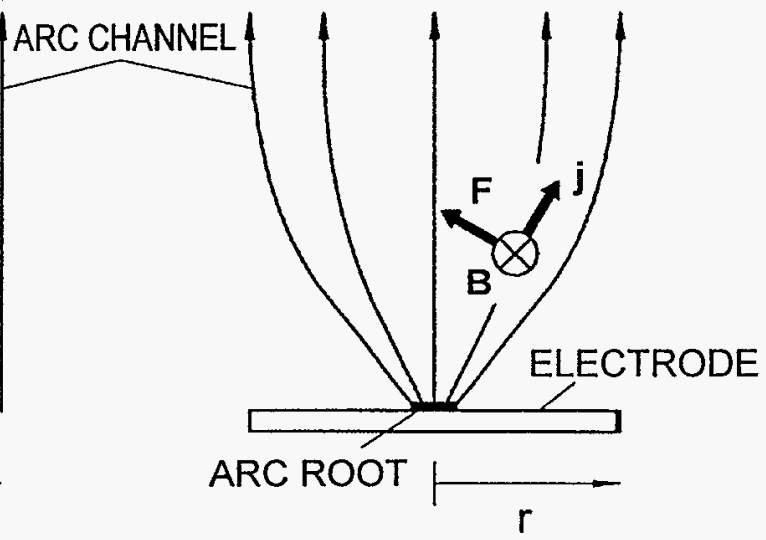

(b)

Figure 1. (a) Symmetric arc with constant current density; (b) constriction of arc root at an electrode spot 
This relationship plays a crucial role in cases in which the radius changes along the length of the arc, such as in the vicinity of the attachment point at the electrode surface, where from experimental observations, it is well known that the arc root radius is very much smaller than the body of the arc column elsewhere. This behavior is shown in Figure 2 for a 200-A arc to a flat electrode. The constriction of the arc root is consistent with the minimum principle (9) known for arcs: Conditions in an arc, like temperature and radius, adjust to minimize arc voltage and thermal losses. The temperature on a metallic surface under a fully developed electrode spot is slightly above the boiling point of the electrode material (approximately $2600^{\circ} \mathrm{C}$ for aluminum, for example); while that within the arc column away from the surface is of the order of $10,000^{\circ} \mathrm{C}$. To minimize thermal losses from the channel into the electrode material, the arc root constricts, thereby reducing the contact area (10). This constriction reaches a limit set by the maximum ion density carried by the arc (9).

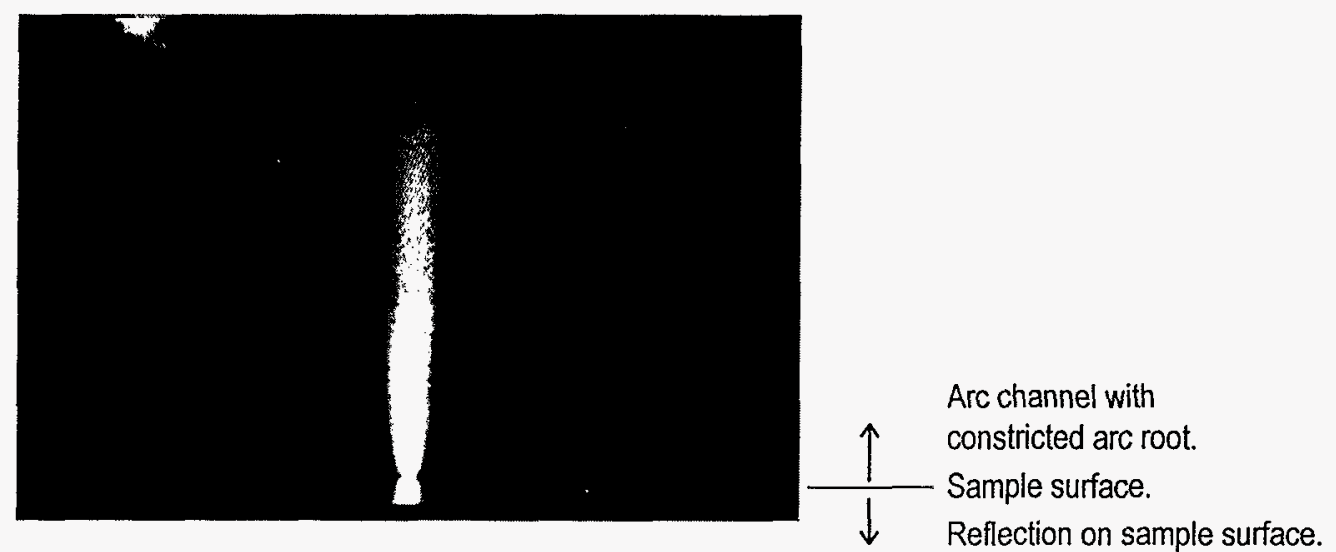

Figure 2. Arc root behavior at a copper electrode surface of a fully established 200-A arc burning in air at atmospheric pressure

\section{TEST EQUIPMENT}

CONSTANT CURRENT GENERATOR-In addition to many other factors, erosion of metal surfaces is a strong function of the amplitude and waveform of the applied current. In the process of validating a thermal spot damage model, it is therefore advantageous to employ initially data produced under constant current conditions. The design of the UAFM constant current generator is shown in Figure 3 . It consists of a set of $6012-\mathrm{V}$ car batteries connected in series. The current flow is initiated by a low energy impulse generator. The current amplitude is set between the limits of about 50 and $1000 \mathrm{~A}$ by adjustable damping resistors $\left(R_{1}, R_{2}, R_{3}\right)$. An inductor $L$ is used to decouple the trigger pulse from the batteries and to stabilize the arc current. The duration of the current (up to $1 \mathrm{~s}$ ) is set by a control unit, which opens the circuit breakers $S_{1}$ and $S_{2} . S_{1}$ is a commercial DC circuit breaker (Siemans $3 W E$ 13) with its three poles connected in series. $S_{2}$ is a pneumatically operated two-pole switch. An example of the resulting current is given in Figure 4.

TEST SETUP-The samples were all tested in the horizontal plane to eliminate the effects of gravity on the molten metal pools produced on the test specimens. The test setup was arranged with six symmetric quasi-coaxial current return conductors (Figure 5) to balance magnetic force effects on the arc. The specimens were fixed in a sample holder as shown in Figure 6. Each sample had a diameter of $70 \mathrm{~mm}$ and a thickness of $5 \mathrm{~mm}$. To enhance the stability of the arc root, a restricting aperture of dielectric material was laid directly onto the surface of the sample. From preliminary tests with different dielectric materials, it was found that 1 -mm-thick Micarta ${ }^{\mathrm{TM}}$ 
performed best for this purpose. Other candidate materials such as mylar and Teflon exhibited a tendency to burn away and produce turbulent gases, which rather than helping to stabilize the arc root at a fixed spot sometimes resulted in just the opposite.

\section{TEST RESULTS}

The UAFM constant current generator was employed in three test series to investigate the following issues related to melting of metal surfaces: the influence of the electrode/gap configuration, the influence of the electrode jet on the arc root, and the achievable test-to-test repeatability under fixed conditions. To permit eventual comparison with the benchmark samples exposed to negative triggered lightning flashes, polarity was chosen such that the test samples formed the anode; that is, the counter electrode was connected to the negative output terminal of the current generator.
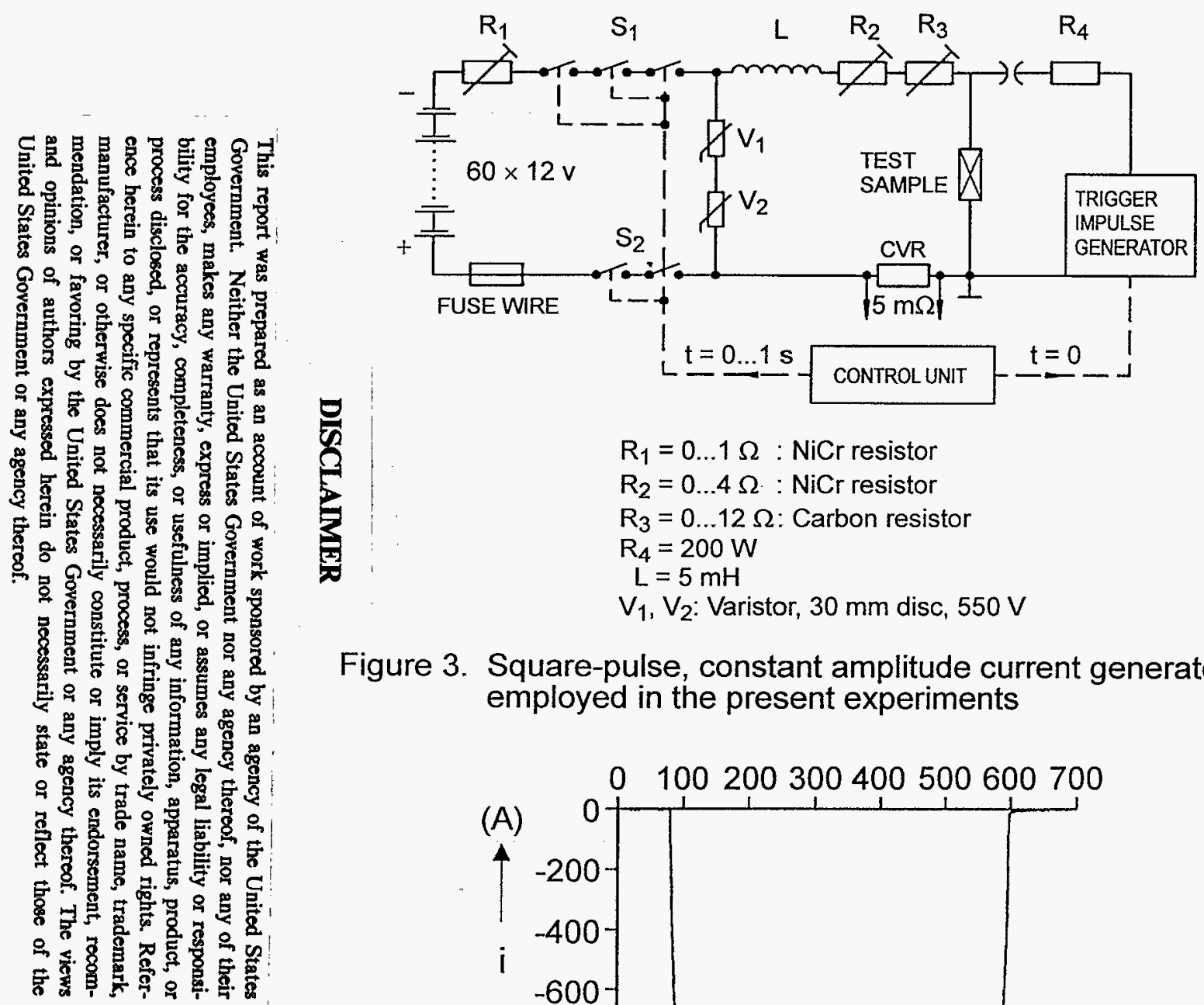

Figure 3. Square-pulse, constant amplitude current generator employed in the present experiments

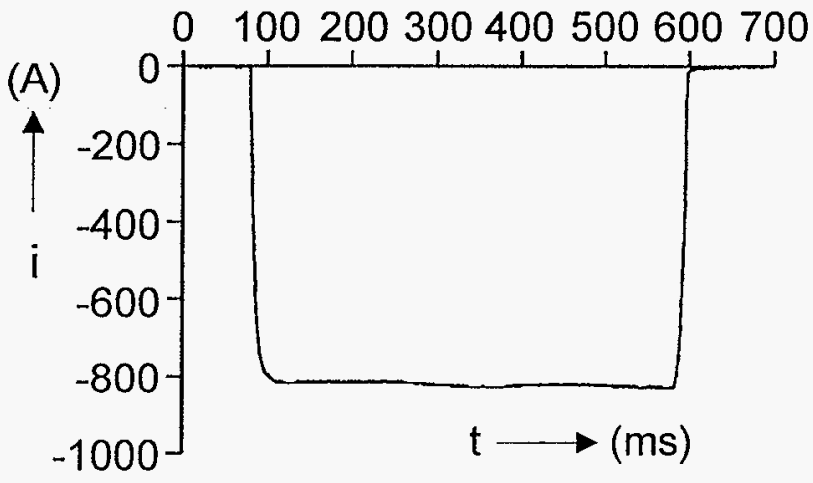

Figure 4. Example output current from the generator shown in Figure 3 


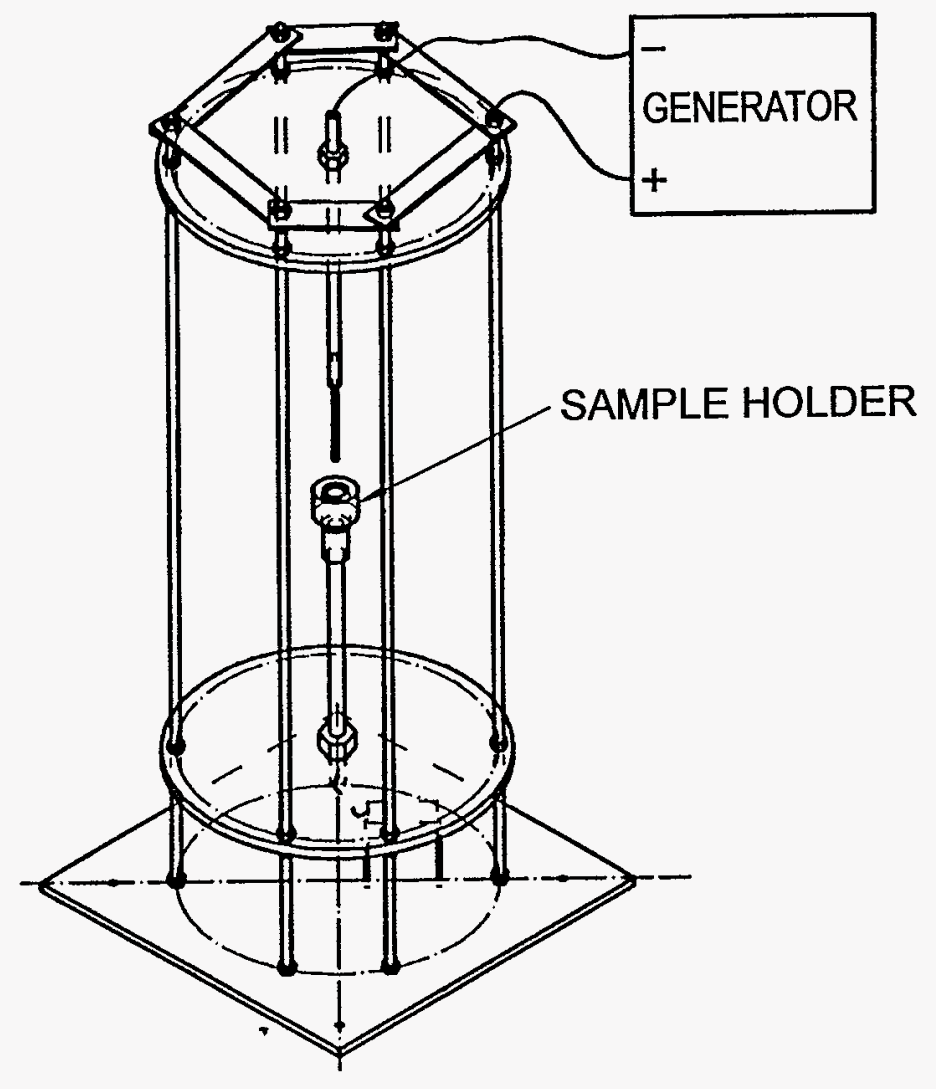

Figure 5. Simulated lightning continuing current test arrangement

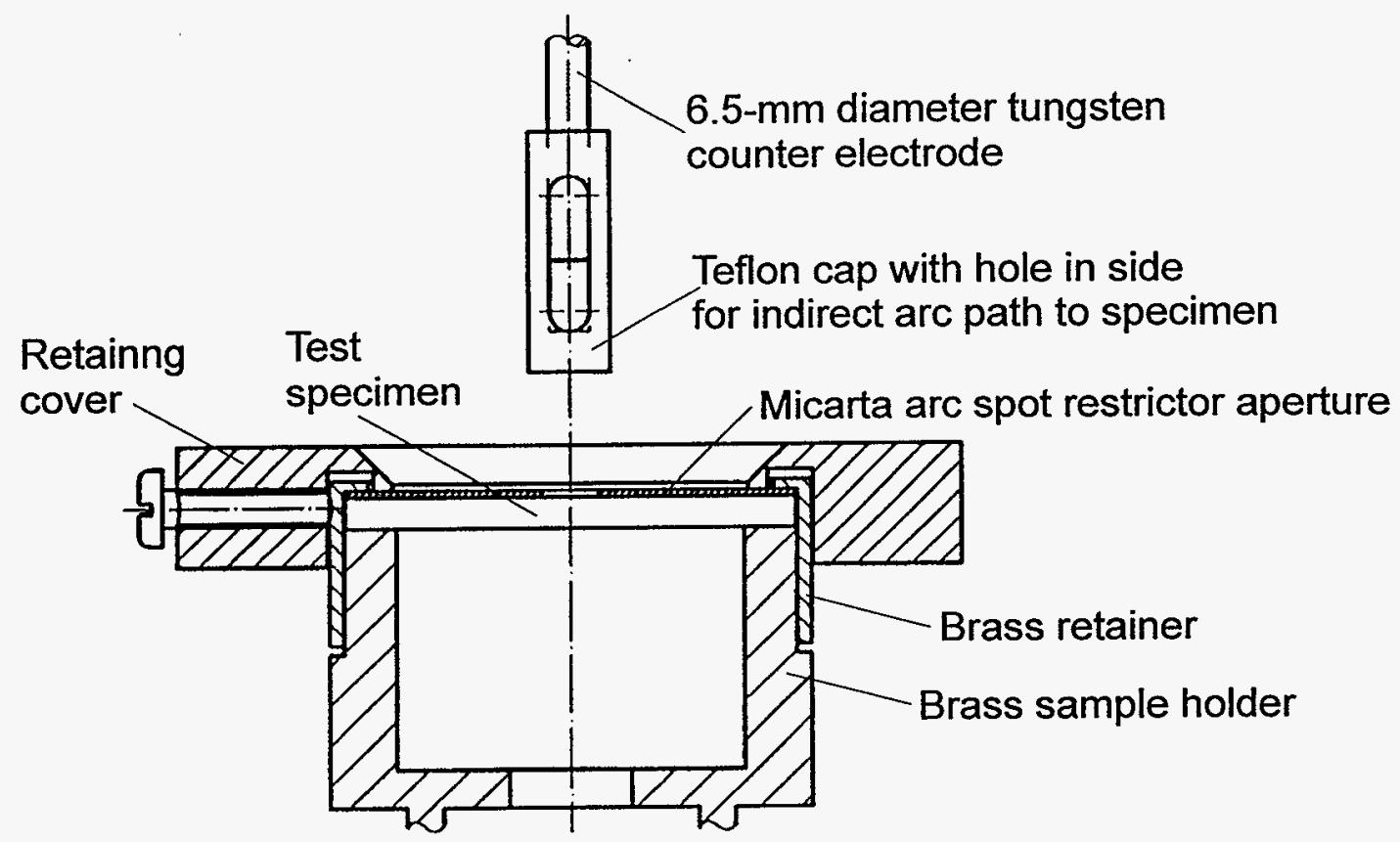

Figure 6. Cross-sectional detail of metallic disk sample holder and jet diverting electrode used during the present experiments 
INFLUENCE OF ELECTRODE AND GAP CONFIGURATION-From earlier experiments (eg., 5, 6) it was well known that the interaction of electrode jets from the test specimen and the counter electrode can significantly influence test results. In principle, these effects can be minimized by either increasing the gap spacing or using an indirect counter electrode designed to divert its jet away from the sample. These alternatives were evaluated by examining the resulting melted pool diameters they produced on four materials: aluminum, copper, ferrous steel, and stainless steel. (Depth of the melt front is also being determined from the sectioned samples, but these data are not as yet available.)

Two types of counter electrodes were investigated: a bare $6.5-\mathrm{mm}$ diameter, flat tipped tungsten rod, and an indirect electrode of the design illustrated in Figure 6 . For each type, the gap spacing was varied between $0.5 \mathrm{~cm}$ and $6 \mathrm{~cm}$. Tests were conducted at nominal current levels of 200 and $800 \mathrm{~A}$, in each case with a 0.5 -s square pulse waveshape. After initial trials, the diameter of the restricting aperture was chosen to be $15 \mathrm{~mm}$ for the tests at $200 \mathrm{~A}$ and $20 \mathrm{~mm}$ for those at $800 \mathrm{~A}$, the larger diameter having been selected for the latter case to avoid the piling up of molten material at the rim of the restrictor. Test results are presented in Figure 7 , showing the molten area on the metal surface as a function of the gap spacing for both types of electrodes at each of the two test current levels. In each case, the area was determined by manually
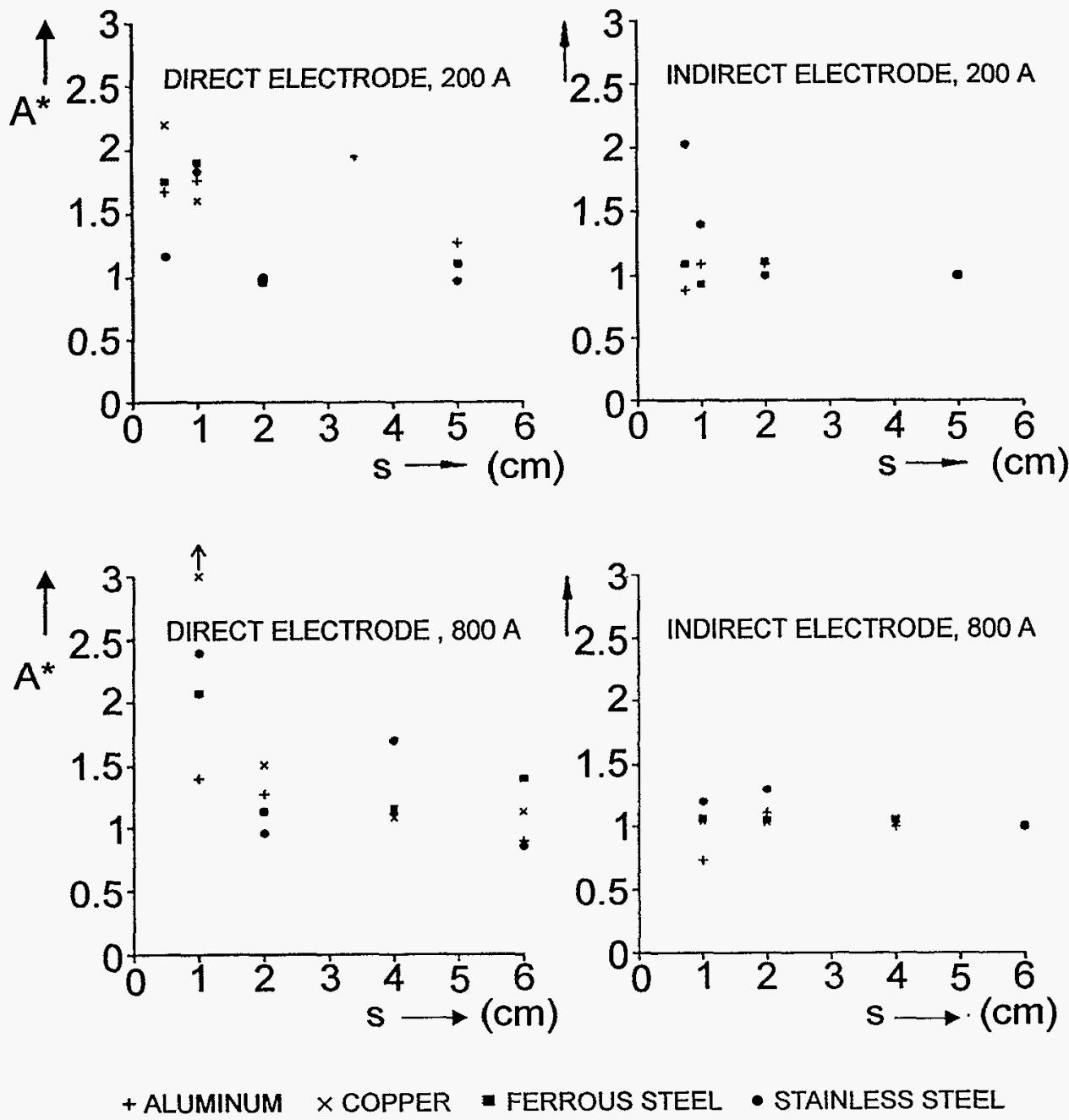

Figure 7. Normalized molten spot areas as a function of interelectrode gap length 
measuring the long and short axes of the spot with a capillar rule and then estimating the total area based on the relationship for the area of an ellipse. More precise determinations are in the process of being generated, but they are not as yet available. In Figure 7, the values of the molten area for the four materials are normalized in each case to the area resulting from the indirect electrode at the maximum gap spacing employed. All aluminum samples were fully penetrated at the $800-A$ level.

From the data of Figure 7, it can be concluded that at $200 \mathrm{~A}$ the spot size becomes independent of the electrode spacing for gaps of about $2 \mathrm{~cm}$ and greater for both the direct and indirect counter electrode types. At $800 \mathrm{~A}$, however, the spot size for the direct electrode is still dependent on the gap spacing at $6 \mathrm{~cm}$, while for the indirect electrode, the spot size stabilizes at $2 \mathrm{~cm}$ or greater.

INFLUENCE OF THE ELECTRODE JET ON THE ARC ROOT-During the first test series described above it was found that in a significant number of cases the arc root was unstable on the surface of the sample. Visual inspection revealed that the arc either jumped around on the surface, resulting in two or more separate spots (especially for copper), or wandered around leaving a continuous track rather than a discrete spot. It was therefore decided to investigate the arc root behavior under the influence of the interaction of the electrode jets in a second test sequence using a VHS video recording system. The camera was operated in a stroboscopic mode, yielding a 1-ms image every $20 \mathrm{~ms}$. These qualitative tests were performed on copper samples at a current of 200-A amplitude and 0.5-s duration.

From the initial video images, it was observed that for a gap spacing of more than $2 \mathrm{~cm}$ the arc did not originate at the center of the test sample, but rather at the rim of the restricting aperture, presumably due to electric field distortion at the edge of the dielectric material. Later, under the influence of the symmetric magnetic field within the test volume, the arc would migrate to the center of the sample leaving a track of molten material behind. To avoid this in the following tests, a guide wire of $0.1-\mathrm{mm}$ diameter copper was used. This wire was carefully aligned over the center of the sample, terminating about $10 \mathrm{~mm}$ above its surface.

From the video records made under these conditions, it was found that there are two major implications of the interaction of the electrode jets from the counter electrode and the specimen surfaces. First, the interaction can result in a more-or-less symmetric disk-like formation between the two electrodes (Figure 8a). Such a disk usually occurs in very short gaps (10). The resulting strong jet in the radial direction can blow out a significant amount of molten material from the pool. If this same material were to

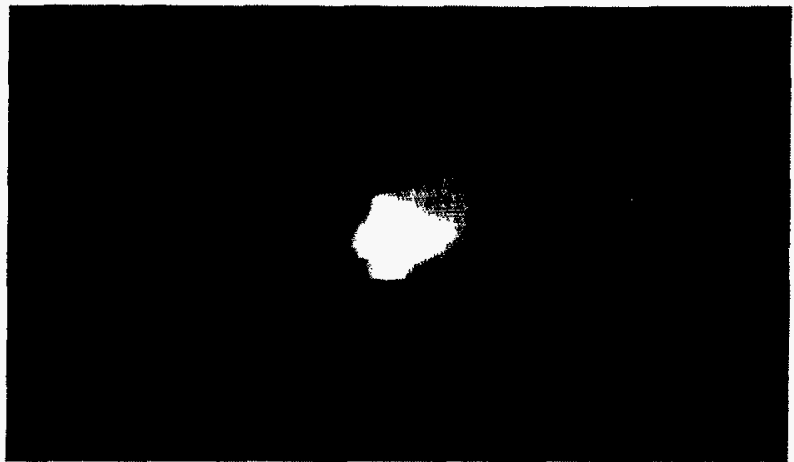

(a)

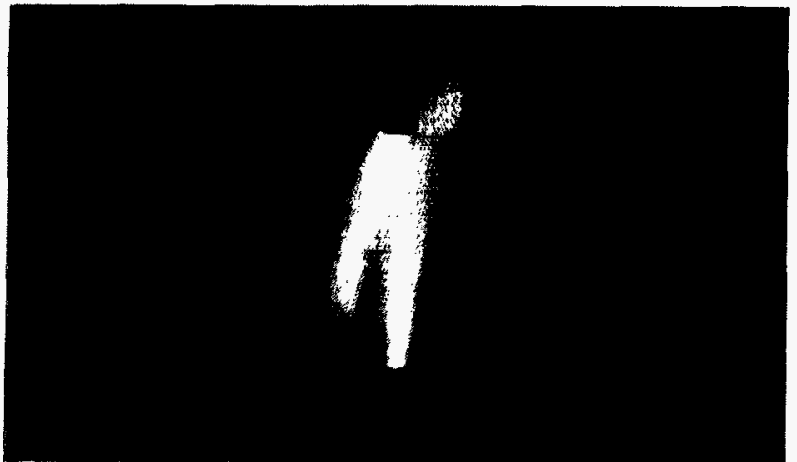

(b)

Figure 8. Observed behavior of jets involving a direct counter electrode (a) disk-like formation with strong radial jet; (b) interaction of jets forcing each other out of the center of the gap 
remain in the pool, it would be further heated and ultimately vaporized. However, the energy needed to accomplish this is about an order of magnitude more than that required for melting alone (11). Hence, if the molten material is removed artificially by the jet action, a larger spot size results for a given amount of energy input to the surface; that is, an overtest results.

Secondly, for longer gaps of a few centimeters or so, the disk formation no longer occurs. Rather, the two electrode jets interact in a manner in which they tend to force each other out from the center of the gap volume (10). This results in severe turbulence of the arc column (8), causing the arc root to skip around erratically on the surface of the sample. This dispersion of the incident energy over multiple spots reduces the depth of maximum penetration that would have occurred had the arc remained stationary in a single spot, and an undertest results. In either case, it is evident that elimination of electrode jet interaction is a fundamental requirement for improving the fidelity of lightning penetration simulations in the laboratory. The effectiveness of the indirect electrode configuration in diverting the jet from the counter electrode, thereby suppressing this undesirable behavior, is demonstrated in Figure 9.

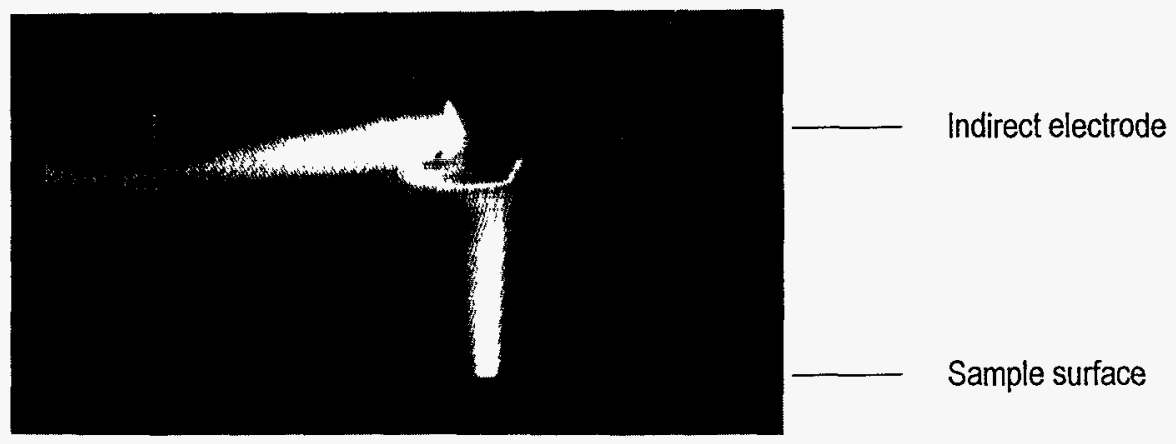

Figure 9. Diversion of jet from an indirect counter electrode configuration

STANDARD TEST CONFIGURATION-On the bases of the measured spot sizes as functions of electrode type and gap spacings and on the video records of electrode jet behavior, the following "standard test configuration" was established. All samples were tested in a horizontal position to avoid gravity effects on the pool of melted material. To avoid electrode jet interactions, the use of an indirect electrode with an interelectrode spacing of $5 \mathrm{~cm}$ was chosen. To suppress arc root migration and keep it stabilized at a single attachment point on the surface, the use of a heat resistant dielectric restrictor aperture, having a diameter of about $10-\mathrm{mm}$ greater than the expected spot size, was employed. Finally, to enhance the probability of the development of a single, stabilized attachment point at the center of the specimen, a fine copper guide wire of $0.1-\mathrm{mm}$ diameter was used, which terminated $10 \mathrm{~mm}$ above the sample.

CONSISTENCY OF TEST RESULTS-To evaluate consistency of the test results achieved with the above defined standard test configuration, ten consecutive tests were performed at both 200 and 800 A on samples of each of four materials: aluminum, copper, ferrous steel, and stainless steel. To avoid full penetration of the aluminum at the 800-A level, the duration of the current was reduced to $160 \mathrm{~ms}$. The pulse width of the current in all the other tests was $500 \mathrm{~ms}$ to allow maximum time for possible arc root movement. The mean values of the resulting molten areas, their standard deviations over the ten tests, and the corresponding maximum and minimum spot sizes are given in Tables 1 and 2, which correspond to the two different test current amplitudes. At $200 \mathrm{~A}$, the arc root wandered on the surfaces of two of the copper samples, the data from which are excluded from Table 1. For ferrous steel at $800 \mathrm{~A}$, only five samples were tested. 
Table 1. Consistency of molten spot sizes at $200 \mathrm{~A}$

\begin{tabular}{lcccc} 
Material & $\begin{array}{c}\text { Mean value } \\
\left(\mathrm{mm}^{2}\right)\end{array}$ & $\begin{array}{c}\text { Standard } \\
\text { Deviation }\end{array}$ & Maximum & Minimum \\
\hline Aluminum & 29.4 & $7.9 \%$ & $+16 \%$ & $-10 \%$ \\
Copper & 6.35 & $8.0 \%$ & $+10 \%$ & $-13 \%$ \\
Ferrous steel & 40.7 & $5.1 \%$ & $+7.1 \%$ & $-5.5 \%$ \\
Stainless steel & 34.9 & $-13 \%$ & $+27 \%$ & $-18 \%$ \\
\hline
\end{tabular}

Table 2. Consistency of molten spot sizes at $800 \mathrm{~A}$

\begin{tabular}{lcccc} 
Material & $\begin{array}{c}\text { Mean value } \\
\left(\mathrm{mm}^{2}\right)\end{array}$ & $\begin{array}{c}\text { Standard } \\
\text { Deviation }\end{array}$ & Maximum & Minimum \\
\hline Aluminum & 51.3 & $7.2 \%$ & $+13 \%$ & $-9.3 \%$ \\
\hline Copper & 56.2 & $2.3 \%$ & $+3.4 \%$ & $-3.8 \%$ \\
\hline Ferrous steel & 134 & $5.3 \%$ & $+5.0 \%$ & $-7.3 \%$ \\
\hline Stainless steel & 143 & $6.9 \%$ & $+7.3 \%$ & $-14 \%$ \\
\hline
\end{tabular}

\section{REFERENCES}

1. White, R.A., "Lightning Simulator Circuit Parameters and Performance for Severe-Threat, High-Action-Integral Testing," Int. Conf. on Lightning and Static Electricity, Orlando, June 1984.

2. Fisher, R.J. and M.A. Uman, "Simulation Fidelity in Lightning Penetration Studies," SAND89-3051, February 1990.

3. Fisher, R.J. and G.H. Schnetzer, "Damage to Metallic Samples Produced by Correlated Measured Lightning Currents," Int. Conf. on Lightning and Static Electricity, Cocoa Beach, April 1991.

4. Schnetzer, G.H. ad R.J. Fisher, "1991 Rocket-Triggered Lightning Test of the DoD Security Operations Test Site (SOTS) Munitions Storage Bunker, Ft. McClellan, Alabama," SAND91-2343, February 1992.

5. Dobbing, J.A., A.W. Hanson, and P.F. Little, "Simulated Lightning Attachments to Aircraft Skins," IEEE Gas Discharge Conf., 1978.

6. Little, P.F., A.W. Hanson, and J.A. Dobbing, "Arcs on Metal Sheets in Simulated Lightning Discharges," IEEE Int. Symposium on EMC, Seattle, 1977.

7. Kern, A., "Simulation and Measurement of Melting Effects on Metal Sheets Caused by Direct Lightning Strikes," Int. Conf. on Lightning and Static Electricity, Cocoa Beach, April 1991.

8. Maecker, H., "Plasmaströmungen in Lichtbögen infolge eigenmagnetischer Kompression," Zeitschrift für Physik, Vol. 141, 1955 pp. 198-216.

9. Rieder, W., "Plasma und Lichtbogen," Vieweg Verlag Braunschweig, 1967. 1985.

10. Burkhard, G., "Schaltgeräte der Elektrotechnik," VDE Verlag Berlin Offenbach,

11. Zischank, W., "Funkenstrecken zur Überspannungsbegrenzung bei direkten Blitzeinschlägen," Dissertation, Universität der Bundeswehr München, 1983. 